\title{
Intracavitary right coronary artery
}

\author{
Jason G Andrade MD FRCPC ${ }^{1}$, Brett G Heilbron MBChB FRCPC FACC ${ }^{1}$, Jonathon A Leipsic MD FRCPC ${ }^{2}$
}

JG Andrade, BG Heilbron, JA Leipsic. Intracavitary right coronary artery. Can J Cardiol 2010;26(6):e211-e212.

Congenital coronary artery anomalies have been reported in fewer than $1.3 \%$ of patients undergoing coronary angiography. Most commonly, they take the form of an anomalous origin of one of the major epicardial vessels or variations in their epicardial course. The presence of an intracavitary course of an intact epicardial coronary artery is a particularly rare entity with two distinct variants described in the literature. While the majority of previous reports were incidentally encountered at the time of open heart surgery or on autopsy, the detection of these abnormalities is likely to significantly increase with the widespread use of advanced cardiac imaging. Although usually clinically benign, these variants impose a myriad of challenges around invasive cardiac procedures. The presence of an intramural or intracavitary course can complicate coronary artery bypass surgery, leading to difficulties in vessel localization as well as bypass grafting. In addition, it is of upmost importance that interventional cardiologists and electrophysiologists are aware of this anomaly because inadvertent disruption of an intracavitary artery can occur at the time of invasive coronary angiography, pacemaker implantation, right heart catheterization or electrophysiology procedure. Electrophysiologists, invasive cardiologists and cardiothoracic surgeons all need to be aware of this anomaly and the implications of this anatomical variant on procedural risk and planning.

Key Words: Congenital heart disease; Coronary vessel anomalies; Intra-atrial coronary artery; Intracavitary coronary artery; Spiral computed tomography

\section{L'artère coronaire droite en position intracavitaire}

On rend compte d'anomalies congénitales de l'artère coronaire chez moins de $1,3 \%$ des patients qui subissent une coronarographie. Elles prennent surtout la forme d'une origine anormale de l'un des principaux vaisseaux épicardiques ou de variations de leur parcours épicardique. Le parcours intracavitaire d'une artère coronaire épicardique intacte est particulièrement rare; deux variantes distinctes sont décrites dans les publications. Bien que la majorité des rapports antérieurs aient été observés par hasard pendant une opération à cœur ouvert ou une autopsie, le dépistage de ces anomalies augmentera probablement de manière considérable avec l'utilisation généralisée de l'imagerie cardiaque avancée. D’ordinaire, ces variantes sont bénignes sur le plan clinique, mais elles imposent une foule de problèmes entourant les interventions cardiaques envahissantes. La présence d'un parcours intramural ou intracavitaire peut compliquer un pontage aortocoronarien et entraîner des difficultés à trouver le vaisseau et à effectuer le pontage. De plus, il est capital que les cardiologues interventionnels et les électrophysiologistes connaissent cette anomalie en raison du risque de déplacer une artère intracavitaire par inadvertance pendant une coronarographie envahissante, l'implantation d'un stimulateur cardiaque, un cathétérisme du cœur droit ou une intervention d'électrophysiologie. Les électrophysiologistes, les cardiologues interventionnels et les chirurgiens cardiothoraciques doivent tous connaître cette anomalie et les répercussions de cette variante anatomique sur le risque et la planification des interventions.

A 46-year-old physician with an intermediate pretest probability but strong family history of premature coronary artery disease was referred for cardiac computed tomography angiography. While the cardiac computed tomography angiography did not demonstrate significant atherosclerotic coronary artery disease, the right coronary artery (RCA) was noted to have an anomalous intracavitary course within the right atrium over a $2.5 \mathrm{~cm}$ segment (Figures 1 to 3 ).

\section{DISCUSSION}

The presence of an intracavitary course of an intact epicardial coronary artery is rarely encountered. To date, two variants have been described: an intracavitary course of the proximal left anterior descending artery into the right ventricle, which is more common and estimated to occur in less than $0.3 \%$ of the population, and an intracavitary course of the RCA into the right atrium in less than $0.1 \%$ of the population $(1,2)$. Although believed to be clinically benign, these variants impose a myriad of potential challenges around invasive cardiac procedures. Inadvertent disruption of an intracavitary artery resulting in left-to-right shunting or distal myocardial ischemia can occur at the time of invasive coronary angiography, pacemaker implantation, right heart catheterization or invasive electrophysiology testing (1-5). Indeed, the complex and multifaceted nature of invasive electrophysiology procedures puts an intra-atrial coronary artery at significant risk of disruption, in which damage to an intracavitary coronary artery may occur during

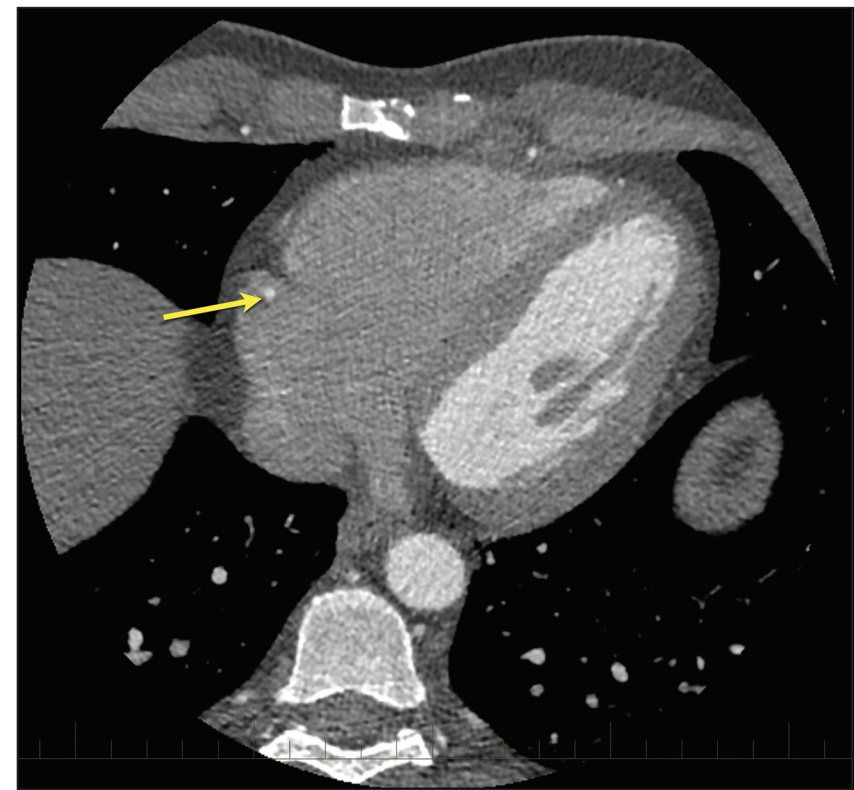

Figure 1) Axial image at the level of the coronary sinus displaying the right coronary artery within the blood pool of the right atrium (yellow arrow)

${ }^{1}$ Division of Cardiology; ${ }^{2}$ Department of Radiology, St Paul's Hospital, Vancouver, British Columbia

Correspondence: Dr Jason G Andrade, University of British Columbia, 9th Floor Cardiology, 2775 Laurel Street, Vancouver, British Columbia V5Z 1 M9.

Telephone 604-320-3715, fax 604-875-5361, e-mail jasonandrade@shaw.ca

Received for publication September 25, 2009. Accepted November 30, 2009 


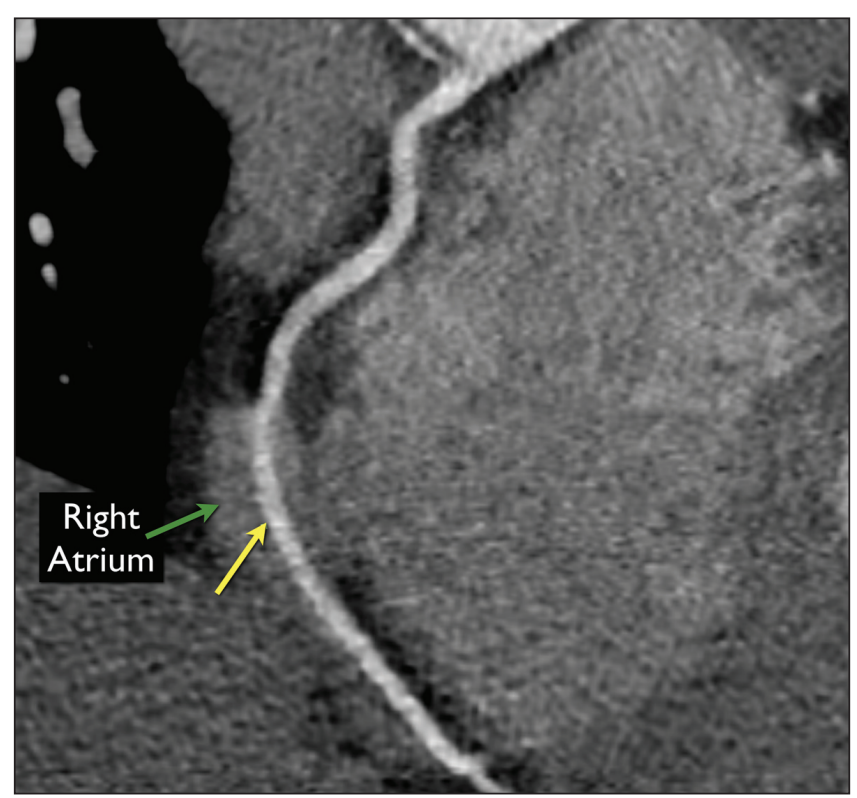

Figure 2) Curved multiplanar reformat displaying the intracavitary course of the right coronary artery (yellow arrow) within the right atrium (green arrow)

intracardiac electrode placement for the diagnostic electrophysiology study, during transseptal puncture for left atrial access, as well as during radiofrequency ablation of ventricular tachyarrhythmias originating in the right ventricle (intracavitary left anterior descending artery) or atrial tachyarrhythmias arising in the right atrium (intracavitary RCA). This particular point is of significant concern because in a significant number of the described cases, the anomalous course of the RCA involves a significant segment of exposed vessel within the atrial chamber (up to $5.5 \mathrm{~cm}$ ) (3-5). As well, the aforementioned exposed segment is often displaced superiorly from the usual position within the atrioventricular groove to a more atrialized location (3-5). In this new locality, the exposed segment may be positioned within the cavotricuspid isthmus, which is a common site of typical atrial flutter ablation.

Likewise, the presence of an intramural or intracavitary course can complicate coronary artery bypass surgery, leading to difficulties in vessel localization as well as bypass grafting. Similarly, the intracavitary course exposes the artery to risk of direct trauma at the time of inferior vena cava or coronary sinus cannulation for cardiopulmonary bypass or retrograde delivery of cardioplegia, respectively. Likewise, during target-vessel dissection and attempted exposure, the right atrial or right ventricular cavity may be inadvertently entered, leading to introduction of air into the right heart and venous bypass cannula. Finally, at the time of myocardial closure, there will be a risk of compromise to the anomalous vessel. As such, any surgical procedure will need to be tailored and individualized $(1,2)$.

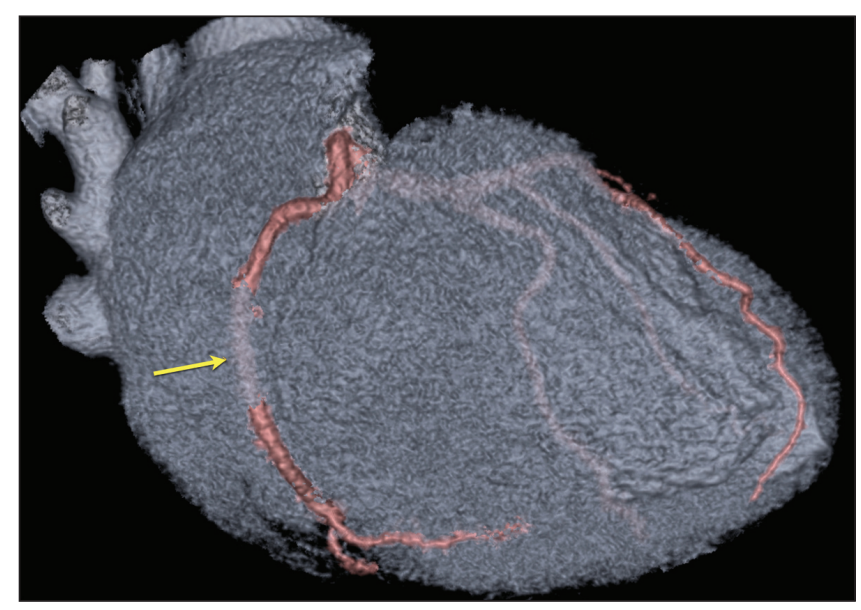

Figure 3) Oblique three-dimensional volume-rendered model displaying the cardiac chambers in transparent grey and the coronary arteries in pink. The yellow arrow denotes the segment of the right coronary artery that travels deep within the right atrium over approximately $2.5 \mathrm{~cm}$

Although intracavitary coronary arteries are historically estimated to only occur in less than $0.5 \%$ of the population, this likely represents an underestimate because the presence of an intracavitary coronary artery is not easily identified by conventional coronary angiography and other noninvasive diagnostic methods. Given the widespread use of advanced cardiac imaging (cardiac computed tomography and cardiac magnetic resonance imaging), the detection of these abnormalities is likely to increase significantly. Electrophysiologists, invasive cardiologists and cardiothoracic surgeons all need to be aware of this anomaly and the implications of this anatomical variant on procedural risk and planning.

\section{REFERENCES}

1. Tovar E, Borsari A, Landa D, Weinstein P, Gazzamiga A.

Ventriculotomy repair during revascularization of intracavitary anterior descending coronary arteries. Ann Thor Surg 1997;64:1194-6.

2. Jalal A, Shackcloth M, Dihmis W. Anomalous course of the right coronary artery in the right atrial wall: A word of caution. Heart Surg Forum 2002;5:300-1.

3. Kolodziej AW, Lobo FV, Walley VM. Intra-atrial course of the right coronary artery and its branches. Can J Cardiol 1994;10:263-7.

4. Rosamond T, Wetzel LH, Lakkireddy D, Ferrell R, Tadros P. Intracameral right coronary artery: Detection by 64 slice coronary computed tomographic angiography and implications for radiofrequency ablation of atrial dysrhythmias. Pacing Clin Electrophysiol 2007;30:1571-4.

5. Scheffel H, Vetter W, Alkadhi H. Intra-atrial course of the right coronary artery: A previously missed anomaly. Eur Heart J 2007;28:1919. 